\title{
Results of atmospheric-lithospheric observations of acoustic radiation in Kamchatka
}

\author{
Igor Larionov ${ }^{1, *}$, Yuriy Marapulets ${ }^{1}$, and Mikhail Mishchenko ${ }^{1}$ \\ ${ }^{1}$ Institute of Cosmophysical Research and Radio Wave Propagation FEB RAS, Mirnaya, 7, Paratunka, \\ Kamchatkskiy kray, 684034, Russia
}

\begin{abstract}
Simultaneous atomspheric-lithospheric acoustic observations have been carried out during autumn-spring periods of 2017-2019 in Kamchatka at "Karymshina" observation site located in the zone of different-rank tectonic faults. A laser strainmeter-interferometer, a seismoacoustic receiver and a microbarometer were installed to realize the observations. It was detected that during deformation disturbances, geoacoustic signals are generated in rocks with relative deformations of $10^{-5}-10^{-7}$ at the place of recording. These signals pass the Earth-atmosphere boundary and are recorded in the air by the ground surface.
\end{abstract}

\section{Introduction}

At the present time, an acute problem in Acoustics is the direction associated with joint investigation of acoustic wave processes at the lithosphere-atmosphere boundary. Investigation of acoustic waves, propagating in solid-gas system, is necessary to construct models for lithosphere, atmosphere, magnetosphere relations that is one of the most important areas in Geophysics.

The lithospheric-atmospheric interaction manifests the most brightly in seismically active regions at the final stage of earthquake preparation [1,2]. Profound interest to the joint consideration of seismoacoustic wave processes is determined by the fact that acoustic waves of infrared range are capable of propagating at long distances and reach ionospheric heights during favorable conditions (low attenuation and scattering, weak refraction in the atmosphere) [3]. Owing to this, they play a considerable role in energy transfer between geospheres.

\section{Instrumentation and observation highlights}

Deformation measurements by a laser strainmeter-interferometer have been carried out at the Laboratory of Acoustic Research IKIR FEB RAS since 2005. The device was constructed according to Mikel'son interferometer scheme and is installed at "Karymchina" measurement site far from anthropogenic noise. In 2016, the staff of the Laboratory of Acoustic Research modernized the hardware-software components of the strainmeter. The advantage of the laser strainmeter against a mechanic analogue is the absence of a mechanic sensitive element. The principle of deformation measurements is that the strainmeter base change causes additional

\footnotetext{
*e-mail: igor@ikir.ru
} 
increment of a phase in a laser radiation wave recorded by a photodiode [4]. When organizing deformation measurements, we chose a scheme of «open» type that means without light guides and without weather effect compensation. Such a scheme imposed some limitations on measurement accuracy which is not less than $10^{-} 8$ during relative deformation recording. Such accuracy is enough to investigate the local deformation process [5, 6].

A three-component piezoceramic geophone is mounted on the strainmeter optical bench end to record geoacoustic signals [7]. It provides transformation of acoustic signals into electric potential proportional to the oscillating acceleration in the frequency range of $0.2-$ $400 \mathrm{~Hz}$. The geophone is installed so that one of the orthogonal components of a recorded acoustic signal (X component) coincides with the strainmeter measuring axis direction [8].

A differential microbarometer ISGM-03M produced by a Scientific Engineering Center «Geophysical measurements», Novosibirsk, is used to measure atmospheric acoustic radiation. It is placed 4 meters from the strainmeter at the depth of 0.5 in a hole covered from precipitation. The microbarometer ISGM-03M is aimed at transformations of air pressure variations into electric signals in the operating frequency band from 0.02 to $100 \mathrm{~Hz}$ and amplitude range from 0.001 to $100 \mathrm{~Pa}$. The operation principle is based on the measurement of elastic membrane displacement relatively a stationary electrode from air pressure effect by a capacitance displacement sensor [9].

An important feature of the experiment is that the devices, placed not far from each other, are covered by three-meter snow layer in winter-spring time that provides temperature stabilization. In order to analyze the weather factor effects, we applied the data from a weather station located 20 away from the strainmeter. We should note that wind velocity, expressed in signal amplitude oscillation amplification, had the strongest effect on instrumental data.

Earth surface deformations, near-surface sedimentary rock acoustic emission, atmospheric acoustic radiation are recorded by a hardware-software complex [10] with the sampling frequency of $1 \mathrm{kHz}$.

\section{Data processing method}

An important part of preliminary processing of the data from different recording systems is time synchronization. Owing to the precise time system including a GPS receiver of high accuracy and the same frequency for records, we succeeded to synchronize the data series with the accuracy up to milliseconds.

Recorded signals were also filtered at the preliminary stage of data processing applying Butterworth band filters with the pass band frequency of $0-0.13,0.13-0.6,0.6-5,5-10,10-30$, 30-50, 50-100 Hz.

To solve the problem of search for simultaneous signals in the data under study, in diurnal files we chose the time intervals at nighttime within the interval between 01:00 and 7:00. That ensured the absence of any noise of anthropogenic origin. The previous papers have already described deformation and barometric [9] as well as deformation and geoacoustic responses [8] on strong seismic events. During data analysis, all the cases of detected simultaneous signals were checked on synchronous recording with seismic events according to the Local Earthquake Catalogue of Kamchatka Branch of FITs EGS RAS. In this paper, we focus on the analysis of synchronous disturbances in deformation, geoacoustic and atmospheric fields in the conditions without earthquakes.

In order to make a joint analysis, we applied the data of relative deformations, their rate, three-component geophone data in the frequency band of $10-30 \mathrm{~Hz}$ from the direction coinciding with the strainmeter axis direction as well as the microbarometer data in the frequency range of $0.6-5 \mathrm{~Hz}$ and $5-10 \mathrm{~Hz}$, where the signals under study manifested the most brightly. 
More than 17 thousand of data fifteen-minute fragments with acoustic and deformation disturbances were chosen for the observation period of October 2017 - April 2018 and October 2018 - April 2019. Then we analyzed the data recorded during the calmest nighttime periods between 01:00 and 7:00 of local time at the absence of industrial noise. About 2500 such fragments were selected. After that we analyzed the data in «manual» mode that resulted in 142 fragments with the most vivid examples of simultaneously recorded signals.

\section{Investigation results}
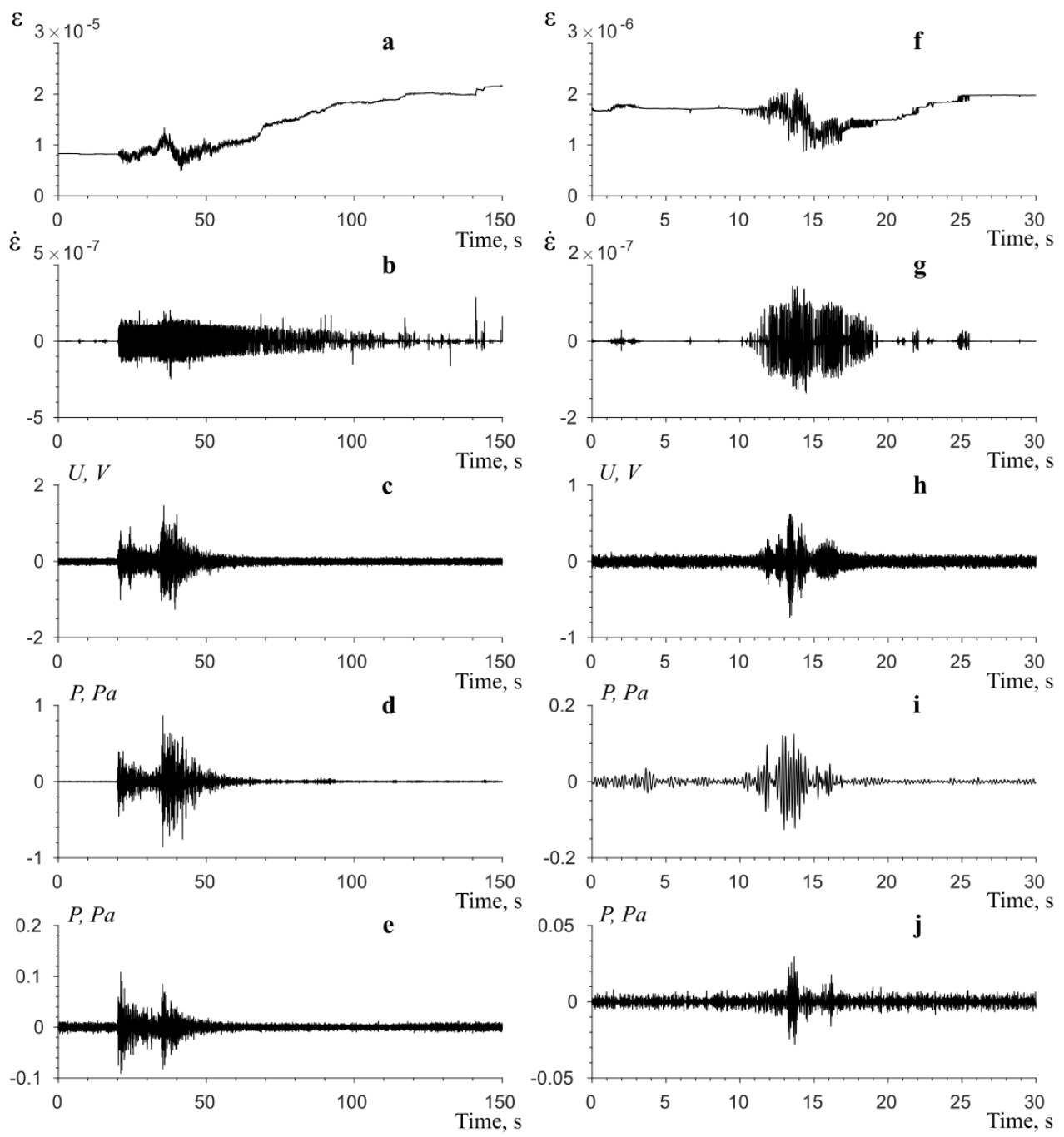

Figure 1. Examples of records of simultaneous signals (left graphs- during seismic wave passage, right graphs - during strong deformation disturbance). Graphs a and $\mathrm{f}-$ relative deformation; $\mathrm{b}$ and $\mathrm{g}$ - deformation rate; $\mathrm{c}$ and $\mathrm{h}-$ geophone horizontal component in the frequency range of $10-30 \mathrm{~Hz}$; acoustic pressure in the frequency range of $0.6-5 \mathrm{~Hz}(\mathrm{~d}, \mathrm{i})$ and $5-10 \mathrm{~Hz}(\mathrm{e}, \mathrm{j})$ 
Figure 1 ( $a, b, c, d, e)$ illustrates a fragment of a signal recorded at the site during the passage of a seismic wave from an earthquake $\left(2017.12 .0215: 11: 38, \mathrm{~K}=11.3,52.53^{\circ} \mathrm{N}\right.$, $159.88^{\circ} \mathrm{E}, \mathrm{H}=44 \mathrm{~km}, \mathrm{R}=120 \mathrm{~km}$ ). The seismic signal is clear on all the graphs, moreover, we can easily detect the times of $\mathrm{P}$ and $\mathrm{S}$ waves arrivals. In this case the relative deformation was about $10^{-5}$. The velocity calculated by the delay time of the seismic wave from the earthquake was $V_{p}=5.9 \mathrm{~km} / \mathrm{s}$ and $V_{s}=3.5 \mathrm{~km} / \mathrm{s}$ that corresponded to reference values [11]. Figure 1 (f, g, h, i, j) shows an example of acoustic pulse record during the absence of seismic events. It is clear from the figure that relative deformation was of the order of $10^{-6}$, the acoustic signal compared to the seismic one was 2-5 times less in amplitude and the disturbances were about 5 times shorter and differed in form.
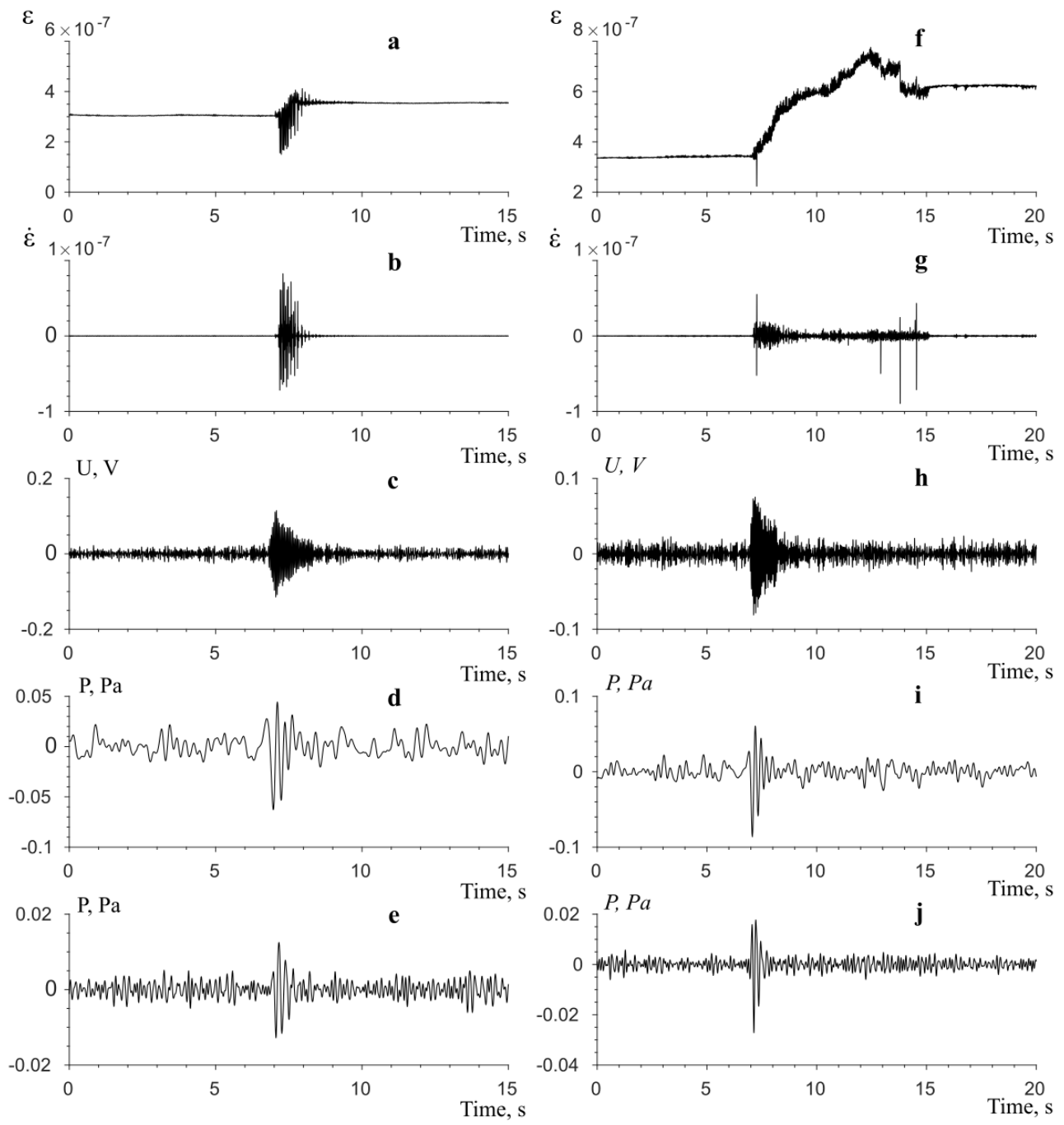

Figure 2. Examples of simultaneous signal records. Graphs a and f - relative deformation; b and g deformation rate; $\mathrm{c}$ and $\mathrm{h}$ - geophone horizontal component in the frequency range of $10-30 \mathrm{~Hz}$; acoustic pressure in the frequency range of $0.6-5 \mathrm{~Hz}(\mathrm{~d}, \mathrm{i})$ and $5-10 \mathrm{~Hz}(\mathrm{e}, \mathrm{j})$ 
Figure 2 illustrates the fragments on which acoustic signals were recorded during the deformations still one order less, i.e. $10^{-7}$. We should note that their values were close to the strainmeter usable sensitivity, however, simultaneous disturbances were also detected in these cases. Figure 2 (a, b, c, d, e) shows a deformation signal and an acoustic response of the length of 1 second. The right part of Fig. 2 (f, g, h, i, j) represents an example of a deformation of the length of 8 seconds, however the acoustic response on it appears during deformation beginning and lasts for about one second just like in the previous case. All that may indicate the fact that an acoustic wave appears at the time of near-surface deformation wave generation. This wave is capable of passing the lithosphere-atmosphere boundary. We should note that more than one hundred signals similar to those illustrated in Fig. 2 were simultaneously recorded by the three observation systems during the period under consideration.

\section{Conclusions}

Thus, it has been shown that during deformation disturbances in rocks with relative deformations of $10^{-5}-10^{-7}$, geoacoustic signals appear at the place of recording. These signals pass the Earth-atmosphere boundary and are recorded in the air by the ground surface. This effect was recorded in the seismically active region for the first time and is topical for construction of models of lithosphere and atmosphere relations including the models of atmospheric disturbances preceding earthquakes.

\section{References}

[1] V.V. Adushkin, A.A. Spivak, S.B. Kishkina, D.N. Loktev, S.P. Solovev, Izvestiya. Physics of the Solid Earth 42(7), 567-584 (2006)

[2] V.A. Gordienko, T.V. Gordienko, N.V. Krasnopistsev, A.V. Kuptsov, I.A. Larionov, Yu.V. Marapulets, B.M. Shevtsov, A.N. Rutenko, Acoustical physics 54(1), 82-93 (2008)

[3] Kuznecov V. V., Plotkin V. V., Homutov S. Yu., Dokl. Earth. Sci., 370(2), 243-248 (2000)

[4] I.A. Larionov, Y.A. Nepomnyashchiy, E3S Web of Conferences, 11 (2016), 00010

[5] I.A. Larionov, Yu.V. Marapulets, B.M. Shevtsov, Solid Earth, 5, 1293-1300 (2014)

[6] Yu.V.Marapulets, B.M. Shevtsov, I.A. Larionov, M.A. Mishchenko, A.O. Shcherbina, A.A. Solodchuk, Russ. J. Pac. Geol., 6(6), 457-464 (2012)

[7] Seysmopriemniki p'ezoelektricheskie A16. Rukovodstvo po ekspluatatsii. 402152.004RE [Piezoelectrical seismometers A16. User manual. 402152.004RE], (ZAO Geoakustica, Moscow, 2006) 40

[8] M.A Mishchenko, Yu.V. Marapulets, I.A. Larionov, L.M. Bogomolov, V.N. Sychev, E3S Web of Conferences, 62 (2018), 02009

[9] I.A. Larionov, Yu.V. Marapulets, Bulletin KRASEC. Phys. \& Math. Sci, 26(1), 86-91 (2019)

[10] I.A. Larionov, E.I. Malkin, Yu.V. Marapulets, M.A. Mishchenko, A.A. Solodchuk, Bulletin KRASEC. Phys. \& Math. Sci., 24(4), 213-225 (2018)

[11] A.G. Nurmukhamedov, V.V. Nediadko, V.A. Rakitov, M.S. Lipatev, Bulletin KRASEC. Earth Sci., 29(1), 35-52 (2018) 